\title{
Contribution to The Knowledge of The Action of Boron in The Dual Structure of a Steel 30MnB5 by Means of X-Ray Diffraction
}

\author{
Growene W Queirós ${ }^{1}$, Ignacio Carabias ${ }^{2}$, Laura García Sanchez*, José M Gómez de Salazar ${ }^{1}$ and Antonio J Criado ${ }^{1}$ \\ ${ }^{1}$ Department of Materials and Chemicals Engineering, Faculty of Chemistry, Complutense University of Madrid, Spain \\ ${ }^{2}$ Faculty of Chemistry, Complutense University of Madrid, Spain
}

\begin{abstract}
The new thermal treatment of subcritical annealing and water quenching, applied to boron steels (30MnB5), which we propose in our research, achieve excellent variability in mechanical properties, as a result of obtaining a very versatile dual structure. In addition, there is a significant reduction in energy consumption and process time, which results in the Life Cycle Analysis (LCA) and process costs. The presence of boron favours the success of the thermal treatment. The explanation of the process has been investigated by means of a metallographic study, mechanical characterization and in this work the results obtained by means of the study of the treated and untreated samples by means of X-Ray diffraction are presented. The presence of very small FeB crystals in the structure are the cause of the dual structure and its good characteristics. They have only been detected by X-Ray Diffraction, although we have also tried Transmission Electron Microscopy with unclear results.
\end{abstract}

Keywords: Boron steel; Dual structure; X-ray diffraction

\section{Introduction}

Obtaining a dual structure in hypo-eutectoid carbon steels is a great advantage in these materials, as it allows two structures with very different properties to be combined: ferrite and martensite.

This results in a wide variety of mechanical properties depending on the proportion of both phases present. In addition to this achievement, it leads to a reduction in energy expenditure and processing times, coupled with quenching in a medium such as water. The end result is an excellent material from a mechanical point of view and with a very good Life Cycle Analysis (LCA), contributing to a lower environmental impact.

The dual steel we studied 30MnB5 has a high hardenability because it contains boron in its chemical composition. As with carbon, boron is soluble only in a very small proportion in the iron crystalline network [1]. The presence of small amounts of boron in a carbon steel allows its alphagenic transformation, favouring its hardenability. By using subcritical hardening thanks to the presence of boron, we save time and temperature in heat treatment, reducing environmental impacts $[2,3]$.

The dual steels, because they have a structure with two phases that provide independent toughness and hardness, represent a very good alternative to other conventional materials. These steels have a homogeneous behaviour during creep, a large deformation hardening zone and a high ductility thanks to the ferrite-martensite combination [4]. This structure has a soft yield mechanical behaviour, low tensile strength/elastic limit ratio and high plastic conformation $[5,6]$. The steels $(30 \mathrm{MnB} 5)$ are applied in the automotive industry, in the manufacture of high-performance screws, agricultural and mining machinery, and in the war industry $[7,8]$.

For a sustainability study linked to steels, the type of impact, the closed chain of Life Cycle Analysis (LCA) and its effects on the environment must be predicted in an ecological way [9-14].

In this research we have tried to see the possible influence of boron on the formation of a dual ferrite-martensite structure. For this, it is necessary to know where the boron is located. The presence of boron in the form of $\mathrm{Fe} 2 \mathrm{~B}$ borides can be in the ferrite, austenite or martensite and, with it, favour or not the formation of martensite in these steels of low carbon content and for subcritical heating of low temperature and short heating times. With transmission electron microscopy it has not been possible to detect the presence of iron borides in the different phases; however, the use of X-ray diffraction has been able to detect the presence of these borides in the different phases. In this way, the presence of these borides is detected in the ferritic matrix of this steel $30 \mathrm{MnB} 5$, in its starting structure, distributed in a regular way. In steel treated thermally by subcritical quenching, borides are selectively found in austenite during heating and, after quenching, in the martensite of the dual structure $[15,16]$.

\section{Experimental Technique}

In this investigation boron steel $30 \mathrm{MnB} 5$ has been used, in bars of different diameters, in reception state of normalized and cold drawn. Specimens of different dimensions have been cut (Figure 1).

The composition of 30MnB5 steel is shown in Table 1.

The thermal treatments applied to the samples for their observation in Scanning and Transmission Electron Microscopy, were:

- Reception status: normalized and cold drawn.

- Water hardening from $900^{\circ} \mathrm{C}$.

\begin{tabular}{|c|c|c|c|c|c|c|}
\hline $\mathbf{C}$ & $\mathbf{M n}$ & $\mathbf{P}$ & $\mathbf{S}$ & $\mathbf{S i}$ & $\mathbf{C r}$ & $\mathbf{B}$ \\
\hline 0.3 & 1.3 & $<0.035$ & $<0.035$ & 0.3 & 0.95 & 0.003 \\
\hline \multicolumn{7}{c|}{ Table 1: Composition of steel (30MnB5), \% by mass content. } \\
\hline
\end{tabular}

*Corresponding author: Laura García Sanchez, Department of Materials and Chemicals Engineering, Faculty of Chemistry, Complutense University of Madrid, Spain, Tel: (+34) 91 3944101; E-mail: gslaura@quim.ucm.es

Received January 24, 2019; Accepted February 15, 2019; Published February 25, 2019

Citation: Queirós GW, Carabias I, Sanchez LG, Salazar JMGD, Criado AJ (2019) Contribution to The Knowledge of The Action of Boron in The Dual Structure of a Steel 30MnB5 by Means of X-Ray Diffraction. J Material Sci Eng 8: 508. doi: 10.4172/2169-0022.1000508

Copyright: @ 2019 Queirós GW, et al. This is an open-access article distributed under the terms of the Creative Commons Attribution License, which permits unrestricted use, distribution, and reproduction in any medium, provided the original author and source are credited. 
Citation: Queirós GW, Carabias I, Sanchez LG, Salazar JMGD, Criado AJ (2019) Contribution to The Knowledge of The Action of Boron in The Dual Structure of a Steel 30MnB5 by Means of X-Ray Diffraction. J Material Sci Eng 8: 508. doi: 10.4172/2169-0022.1000508

- Subcritical annealing at $770^{\circ} \mathrm{C}$, for 15 minutes and quenching in water [2].

The metallographic preparation was done in a conventional way for the samples observed in Scanning Electron Microscopy [2] and for $\mathrm{X}$-Ray Diffraction (Figure 1). The equipment used for the Scanning Electron Microscopy is a JEOL JSM 6400, operated at $20 \mathrm{KeV}$; while for the X-Ray tests a Philips diffractometer model X'PERT has been used, with $\mathrm{Ka}$ of the $\mathrm{Cu}(0.15405 \mathrm{~nm})$ with a voltage of $45 \mathrm{KV}$, a current intensity of $40 \mathrm{~mA}$ and a radius of incidence of 320 , from a Cis-Extres process.

For Transmission Electron Microscopy, the preparation of the samples meant that they were thinned by electrolytic polishing, in an electrolytic polisher model LectroPol-5, applying a current of $2^{\mathrm{a}}$ and $40 \mathrm{v}$, during 12 seconds, at a temperature of $22^{\circ} \mathrm{C}$. The samples were thinned by electrolytic polishing, in an electrolytic polisher model LectroPol-5, applying a current of $2^{\mathrm{a}}$ and $40 \mathrm{v}$, during 12 seconds, at a temperature of $22^{\circ} \mathrm{C}$. The electropolished sample was cleaned by plasma in a Fischione model 1020 for 5 minutes. The equipment used for the Transmission Electron Microscopy is a JEOL 2000-FX equipped with Oxford Link hardware, for EDS-EDX microanalysis, and operated at $200 \mathrm{KeV}$. In addition, observations were made with a more powerful equipment model JEOL 2100-HT, equipped with an Oxford Link hardware, for EDS-EDX microanalysis, and operated at $400 \mathrm{KV}$.

\section{Results}

The steel reception structure studied in this research, $30 \mathrm{MnB}$, consists of a ferritic matrix of grains elongated in the direction of mechanical behaviour, with dispersed iron carbides of very irregular morphology. These iron carbides are associated in colonies (Figure 2).

This steel was subjected to a subcritical annealing heat treatment

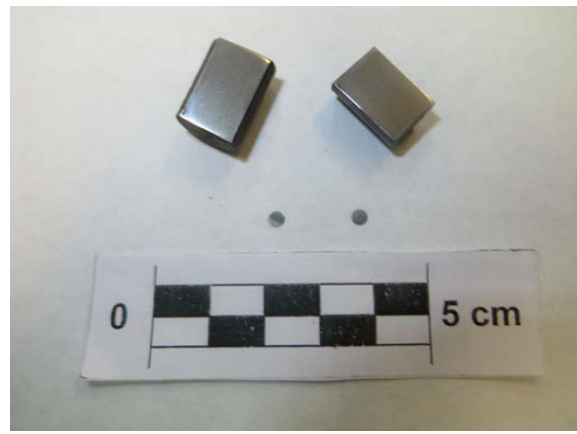

Figure 1: Boron steel specimens 30MnB5 used.

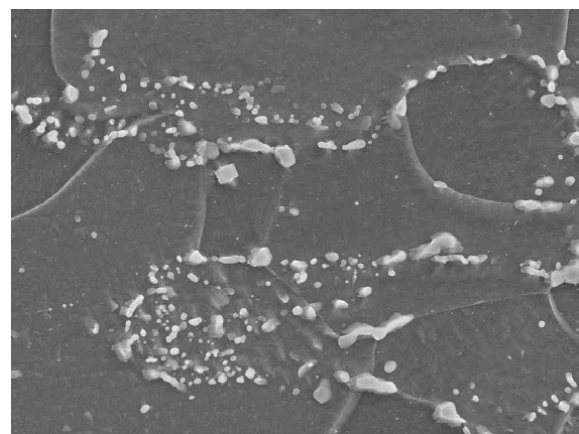

Figure 2: Microstructure of steel $30 \mathrm{MnB5}$ in its receiving state. Iron carbide colonies are observed in a ferritic matrix. at $770^{\circ} \mathrm{C}$ for 15 minutes and then tempered in water. The structure obtained with this treatment is dual-phase, formed by martensite and ferrite crystals (Figure 3).

A conventional heat treatment of annealing at $900^{\circ} \mathrm{C}$ for 30 minutes was also applied, followed by water quenching. The structure obtained with this treatment is total martensitic (Figure 4).

In this research we have tried to verify where boron is found, in the form of iron borides, and its location in the different phases of boron steel without heat treatment, with conventional heat treatment of hardening and with subcritical heat treatment of hardening. By means of Transmission Electron Microscopy in the described equipment (experimental technique section) we have not been able to observe the existence and location of iron borides (Figure 5). Possibly, this is due to their small size. So we try to detect them by X-Ray Diffraction.

The presence of boron in the form of borides is noted in X-ray diffractograms.

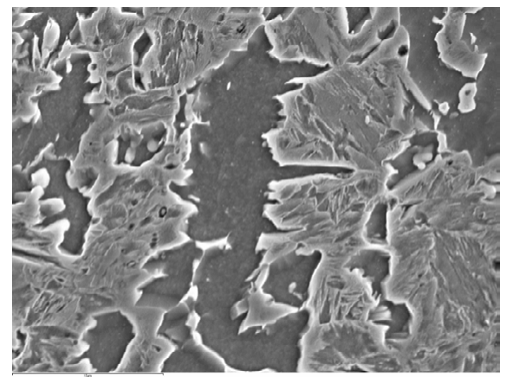

Figure 3: Microstructure of steel 30MnB5 after thermal treatment of subcritical annealing at $770^{\circ} \mathrm{C}$ and subsequent quenching in water. The ferrite and martensite crystals, corresponding to the dual structure, can be observed.

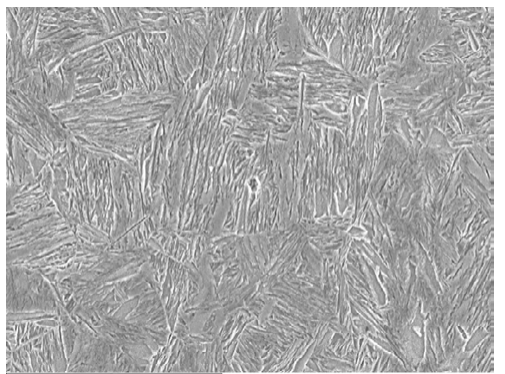

Figure 4: Martensitic microstructure of steel $30 \mathrm{MnB} 5$ after conventional heat treatment of annealing at $900^{\circ} \mathrm{C}$ followed by quenching in water.

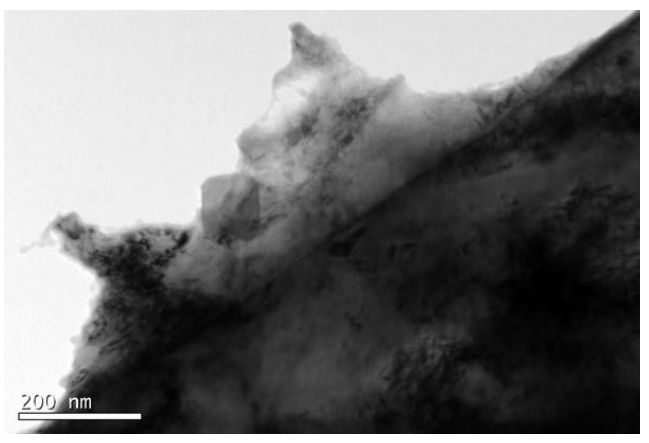

Figure 5: Microstructure of steel $30 \mathrm{MnB} 5$ after subcritical heat treatment at $700^{\circ} \mathrm{C}$ followed by water quenching. TiO crystals are observed. 
Citation: Queirós GW, Carabias I, Sanchez LG, Salazar JMGD, Criado AJ (2019) Contribution to The Knowledge of The Action of Boron in The Dual Structure of a Steel 30MnB5 by Means of X-Ray Diffraction. J Material Sci Eng 8: 508. doi: 10.4172/2169-0022.1000508

Page 3 of 4

In steel heated to $770^{\circ} \mathrm{C}$ for 15 minutes and tempered in water, iron borides are integrated and dissolved in the austenite, abandoning the ferrite, due to its gammagen character, and favouring the water quenching of the steel. Therefore, during heating, boron passes almost exclusively to austenite, remaining retained in austenite, which favours its quenching in water; iron borides appearing in the martensitic phase, as can be seen in the diffractogram in Figure 6.

If we heat the steel to $900^{\circ} \mathrm{C}$ for 30 minutes, the gammagen character of the boron favours its dissolution in the austenite, which this time is massive, transforming and favouring the appearance of martensite in the whole structure during water tempering, as can be seen in the difractogram in Figure 7.

Another data that may be relevant is to check, where are the iron borides in the receiving steel. The difractograms carried out on steel $30 \mathrm{MnB} 5$ show the generalized presence of these iron borides in the ferritic matrix, distributed in a regular way, as can be seen in the difragtogram in Figure 8.
The X-Ray diffraction allow to detect the presence of iron borides in the different phases of the steel $30 \mathrm{MnB} 5$ and, therefore, its action on the martensitic transformation in the dual phase structure.

\section{Conclusions}

Transmission Electron Microscopy has not provided us with information on the presence of iron borides in the phases of dual-phase steel 30MnB5. The use of X-Ray Diffraction has been very useful to detect this presence.

$30 \mathrm{MnB} 5$ steel is easily heat-treated to obtain a dual-phase structure, because boron almost massively dissolves in the austenitic phase during heating to $770^{\circ} \mathrm{C}$ for 15 minutes and leaves the ferritic phase remaining during this subcritical annealing. Tempering from $770^{\circ} \mathrm{C}$ in water allows the boron's tempering action to concentrate on the austenite colonies formed and favour their transformation to martensite.

In the case of annealing at $900^{\circ} \mathrm{C}$, boron is distributed throughout the austenitic structure, favouring transformation to total martensite

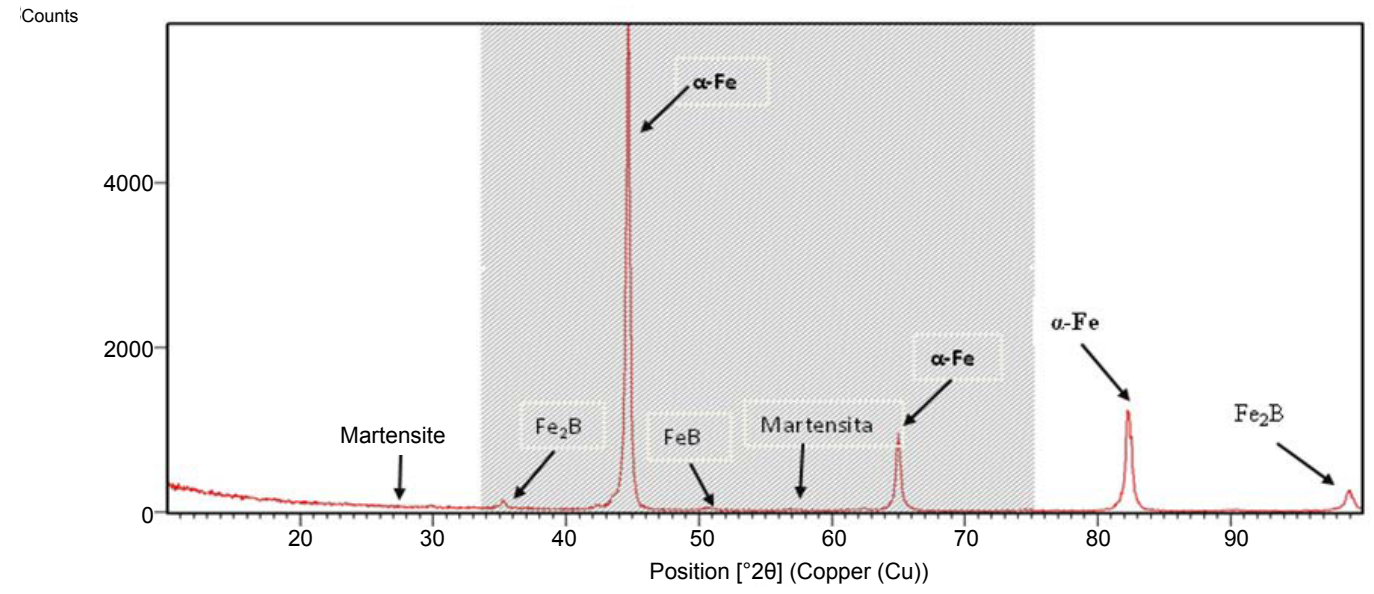

Figure 6: Difragtogram of the steel $30 \mathrm{MnB5}$ in its state of reception.

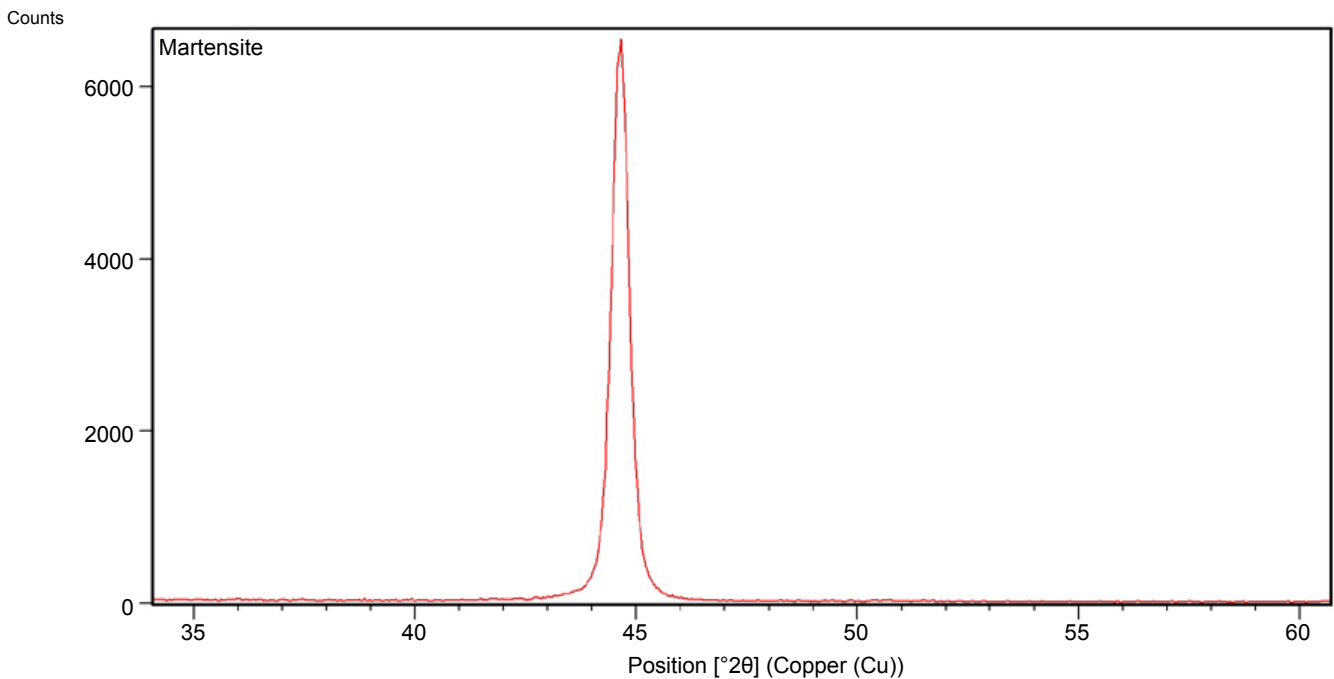

Figure 7: Difragtogram of steel $30 \mathrm{MnB} 5$ after conventional heat treatment of annealing at $900^{\circ} \mathrm{C}$ followed by quenching in water. Boron is found in the form of borides homogeneously distributed throughout the martensitic phase. 
Citation: Queirós GW, Carabias I, Sanchez LG, Salazar JMGD, Criado AJ (2019) Contribution to The Knowledge of The Action of Boron in The Dual Structure of a Steel 30MnB5 by Means of X-Ray Diffraction. J Material Sci Eng 8: 508. doi: 10.4172/2169-0022.1000508

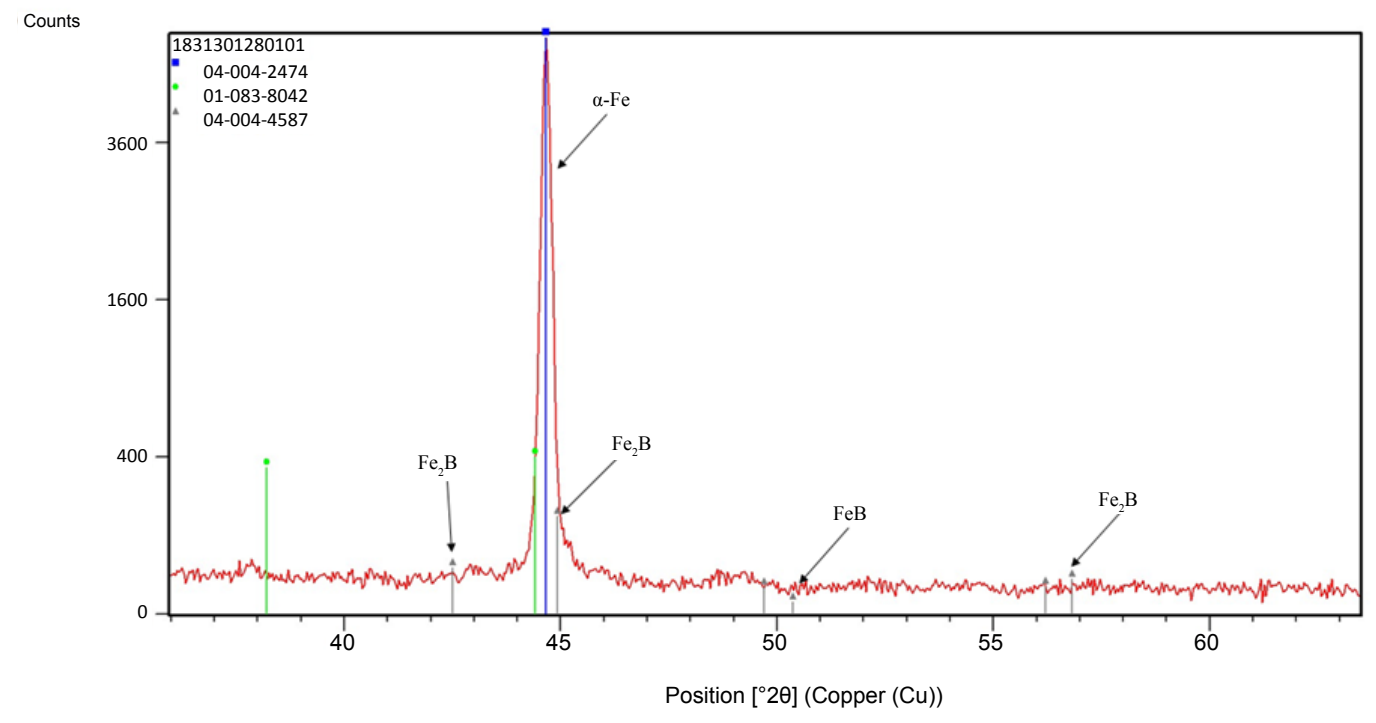

Figure 8: Difragtogram of steel $30 \mathrm{MnB} 5$ after subcritical heat treatment at $700^{\circ} \mathrm{C}$ followed by water quenching.

during water quenching. This fact is corroborated in the difragtogram carried out on steel $30 \mathrm{MnB} 5$, annealed at $900^{\circ} \mathrm{C}$ for 30 minutes and tempered in water.

It is clear from the X-Ray difragtograms that the selective preference of boron for austenite allows it to concentrate on the proportion of austenite formed during the subcritical annealing of 30MnB5 steel at $770^{\circ} \mathrm{C}$ for 15 minutes, favouring the presence of the dual-phase structure after it has been quenched in water.

\section{References}

1. López-Chipres E, Tesis doctoral (2008) Study of the hot creep behavior of an advanced high strength steel with low carbon content NiCrVCu microalloyed with boron. IIM-UMSNH, Morelia, México.

2. Queirós GW, Sánchez LG, Salazar JMGD (2018) Portal AJC: Improved Wear Resistance of Boron Steels by Subcritical Annealing and Hardening with Production Cost Savings and Lower Environmental Impact. J Material Sci Eng 7: $1-4$.

3. Garcia SL, Criado Portal AJ (2015) Steel of Boron with Dual Structure for Automobile Screws, Reducing Manufacturing Costs and Environmental Impact. J Material Sci Eng 4: 1-4.

4. Monsalve A, Artigas A, Castro F, Colás R, Houbaert Y (2011) Characterization of dual-phase steels obtained by hot rolling. Metallurgy Magazine 47: 5-14.

5. Garmón Garrido J (2014) Study of the microstructural evolution and mechanical properties in the ZAT of martensitic ferrite steels submitted to localized TT.

6. Quintana HMJ, González RO (2010) Propiedades mecánicas de aceros de fase dual de grano ultrafino. Escuela de Ingeniería, Universidad Panamericana, México DF.

7. He L, Jin Z, Lu J, Tang J (2002) Modulated structures of Fe-10Mn-2Cr-1.5 C alloy. Mater Des 23: 717-720.

8. Mazinani M, Poole WJ (2007) Effect of martensite plasticity on the deformation behavior of a low-carbon dual-phase steel. Metall Mater Trans A 38: 328-339.

9. Wiedmann T, Minx J (2008) A Definition of Carbon Footprint In: C. C. Pertsova, Ecological Economics Research Trends, Nova Science Publishers, Hauppauge NY, USA, pp: 1-11.

10. Marín GHC (2014) Life Cycle Assessment (LCA) of steel making process. National University of Colombia, Manizales, Colombia.

11. ICONTEC (2007) Environmental management-Life cycle assessmentPrinciples and framework. NTC-ISO14040.

12. IPCC (2014) Climate Change 2013: The Physical Science Basis. Contribution of Working Group I to the Fifth Assessment Report of the Intergovernmental Panel on Climate Change; Cambridge University Press: Cambridge, UK; New York, NY, USA, pp: 659-74.

13. Pandey D, Agrawal M, Pandey J (2010) Carbon footprint: current methods of estimation. Environmental Monitoring and Assessment 178: 135-160.

14. LCM (2005) Innovation by Life Cycle Management (Programme). Barcelona, España.

15. Christian JW (1975) The theory of transformation in metals and allows Pergamon, Oxford.

16. Shao G, Tsakiropoulos P (1994) Prediction of phase selection in rapid solidification using time dependent nucleation theory. Acta Metall Mater 42 : 2937-2942. 